\title{
Serum level of IL-1ra was associated with the treatment of latent tuberculosis infection in a Chinese population
}

\author{
Haoran Zhang ${ }^{1 \dagger}$, Xuefang Cao ${ }^{1 \dagger}$, Henan Xin¹, Jianmin Liu², Shouguo Pan ${ }^{3}$, Ling Guan², Fei Shen², Zisen Liu,
} Dakuan Wang ${ }^{3}$, Xueling Guan ${ }^{2}$, Jiaoxia Yan ${ }^{3}$, Boxuan Feng ${ }^{1}$, Na Li ${ }^{4}$, Qi Jin ${ }^{1}$ and Lei Gao ${ }^{1 *}$ (i)

\begin{abstract}
Background: Dynamically changed levels of serum cytokines might predict the development of active TB from latent tuberculosis infection (LTBI) and monitor preventive treatment effectiveness. The aim of the study was to identify potential serum cytokines associated with LTBI treatment which might predict active disease development in a Chinese population.

Methods: Based on a randomized controlled trial aiming to explore short-course regimens for LTBI treatment, the dynamic changes of serum cytokines determined by bead-based multiplex assays were investigated for the participants who developed active TB during follow-up and age and gender matched controls stayed healthy.

Results: Totally, 21 patients diagnosed with active tuberculosis (TB) during the 2-year follow-up (12 from treated groups and 9 from untreated controls) and 42 age and gender matched healthy controls (24 from treated groups and 18 from untreated controls) were included in the study. Before treatment, serum IL-1ra was statistically higher among those who developed active disease during follow-up as compared with those stayed healthy. As for treated participants, the levels of IL-1 ra were significantly lower after treatment in comparison with those before treatment both in active TB group $(p=0.002)$ and non-TB group $(p=0.009)$. For untreated participants, the levels of IL-1 ra were not statistically different between different time points both in active TB group $(p=0.078)$ and non-TB group $(p=0.265)$.

Conclusion: Our results suggested that declined serum level of IL-1ra was associated with LTBI treatment. Further studies are needed to verify whether it could be used to evaluate LTBI treatment and to predict active disease development.
\end{abstract}

Keywords: Latent tuberculosis infection, Preventive treatment, Cytokines, IL-1ra, Disease development

\footnotetext{
* Correspondence: gaolei@ipbcams.ac.cn

'Haoran Zhang and Xuefang Cao contributed equally to this work.

${ }^{1} \mathrm{NHC}$ Key Laboratory of Systems Biology of Pathogens, Institute of Pathogen Biology, and Center for Tuberculosis Research, Chinese Academy of Medical

Sciences and Peking Union Medical College, No. 9 Dong Dan San Tiao,

Dongcheng District, Beijing 100730, China

Full list of author information is available at the end of the article
}

(C) The Author(s). 2020 Open Access This article is licensed under a Creative Commons Attribution 4.0 International License, which permits use, sharing, adaptation, distribution and reproduction in any medium or format, as long as you give appropriate credit to the original author(s) and the source, provide a link to the Creative Commons licence, and indicate if changes were made. The images or other third party material in this article are included in the article's Creative Commons. licence, unless indicated otherwise in a credit line to the material. If material is not included in the article's Creative Commons licence and your intended use is not permitted by statutory regulation or exceeds the permitted use, you will need to obtain permission directly from the copyright holder. To view a copy of this licence, visit http://creativecommons.org/licenses/by/4.0/ The Creative Commons Public Domain Dedication waiver (http://creativecommons.org/publicdomain/zero/1.0/) applies to the data made available in this article, unless otherwise stated in a credit line to the data. 


\section{Background}

About a quarter of the world's population were estimated to be latently infected with Mycobacterium tuberculosis (M.tb) [1]. It was estimated that $5-10 \%$ infections might develop active tuberculosis (TB) during their lifetime [2, 3]. Scaling up latent tuberculosis infection (LTBI) testing and treatment among individuals at highrisk of developing active disease is a critical priority action for the END TB [4-6]. Currently, directly observe the decline of incidence is the standard way to evaluate the protective effect of the preventive treatment, which usually needs a long follow-up period and huge resource input. Tuberculin Skin Test (TST) and Interferon- $\gamma$ Release Assays (IGRAs) both are immunological tests to identify infections, but they are poor at predicting the development of active disease [7, 8]. Accessible surrogate biomarkers could reflect the effectiveness of LTBI treatment are warranted in the era of prevention centered.

It has been recognized that cytokines and chemokines play important roles in shaping immunity against TB by polarizing $\mathrm{T}$ cell subsets responses, modulating immune cell trafficking, and regulating inflammatory responses [9]. Some exploratory studies evaluated specific antigen stimulated or un-stimulated serum cytokine biomarkers other than IFN- $\gamma$ for monitoring the potential effect of anti-TB treatment, such as TNF- $\alpha$, IL-10, IL-6, IL-1ra, MIP-1 $\beta$, IL-2/IFN- $\gamma$ and IP-10 [10-14]. Nevertheless, few studies have been conducted to assess the performance of un-stimulated serum cytokine levels in monitoring host response to preventive treatment of LTBI [12]. Therefore, the aim of the present study was to identify potential cytokine biomarkers associated with prophylactic treatment which might also predict the development of TB from LTBI.

\section{Methods}

\section{Study population}

Study participants in current study were selected from a randomized controlled trial (RCT) exploring shortcourse treatment regimen for 50-70 years rural residents with LTBI in China. Detailed information of the trial has been published elsewhere [6]. Briefly, all participants aged 50 to 70 years old with QuantiFERON TB Gold InTube (QFT, Qiagen, USA) positive result (TB Ag-Nil $\geq 0.35 \mathrm{IU} / \mathrm{ml}$ ) and without current active $\mathrm{TB}$ at baseline survey were included for a RCT. They were randomly classified into three groups (Group A: 8 weeks regimen of once-weekly RPT plus INH, between 7 November 2015 and 2 January 2016; Group B: 6 weeks of twiceweekly RPT plus INH, between 25 November 2015 and 2 January 2016; Group C: untreated controls). During the 2-year follow-up after the preventive treatment, a total of 30 incident cases of active TB were diagnosed. Among them, 21 active TB cases (Group $\mathrm{A}=8$; Group
$\mathrm{B}=4$; Group $\mathrm{C}=9$ ) with available blood samples and who completed the assigned regimes were included in current study. In addition, 42 gender and age matched non-TB subjects (Group $\mathrm{A}=16$; Group $\mathrm{B}=8$; Group $C=18$ ) were included in the present study as well. The protocol of the present study has been approved by the Ethics Committees of the Institute of Pathogen Biology, Chinese Academy of Medical Sciences (IDs: IPB-2015-5 and IPB-2016-8). All participants have signed the written informed consent.

\section{Cytokines measurements}

Blood samples at baseline (T0, 1 week before starting treatment) and at the end of preventive treatment (T1, 1 week after completing the treatment) have been collected and retained. Ready-made cytokine Kit (Bio-Rad Laboratories, Hercules, CA, USA) which could simultaneously detect forty-eight cytokines (CTACK, Eotaxin, GRO- $\alpha$, interferon-inducible protein (IP)-10/CXCL10, macrophage chemoattractant protein (MCP-1)/MCAF, MCP-3, MIF, MIG, macrophage inflammatory protein$1 \alpha$ (MIP-1 $\alpha)$, MIP- $1 \beta$, PDGF-BB, RANTES, SDF- $1 \alpha$, granulocyte macrophage colony stimulating factor (GMCSF), G-CSF, SCF, M-CSF, VEGF-A, LIF, Basic FGF, HGF, $\beta$-NGF, SCGF- $\beta$, IFN- $\alpha 2$, IFN- $\gamma$, tumor necrosis factor (TNF)- $\alpha$, TNF- $\beta$, TRAIL, Interleukin (IL)- $1 \alpha$, IL$1 \beta$, IL-1ra, IL-2R $\alpha$, IL-2, IL-3, IL-4, IL-5, IL-6, IL-7, IL-8, IL-9, IL-10, IL-12(p70), IL-12(p40), IL-13, IL-15, IL-16, IL-17A and IL-18) were used. Levels of the selected cytokines were determined for each undiluted and unstimulated serum sample $(50 \mu \mathrm{l})$ by magnetic bead suspension array using the Bio-Plex Pro Human Cytokine panels according to the manufacturer's instructions. Cytokines with $>50 \%$ of the samples below the lower detection level (LDL) of the assay will be excluded from further statistical analysis. Additionally, cytokines with occasional values $(<50 \%)$ below the LDL were assigned an averaged value between 0 and the lowest detectable level in each assay plate [15].

\section{Statistical analysis}

Statistical analyses were performed using SAS 9.4 version (SAS institute, Cary, NC) and GraphPad Prism 5 (GraphPad software, San Diego, CA). Participants who completed $\geq 90 \%$ doses of the therapy were defined as completed the regimes. The Chi-square and Fisher's exact tests were used to compare the distribution of categorical variables across groups. The level of cytokines was presented with median (Q25-Q75). Wilcoxon rank sum test was used to compare cytokine responses between different participants at the same time-point. Wilcoxon signed rank test was used to evaluate the cytokine responses for the same person at different time points. To assess the predictive ability of the cytokines, 
receiver operating characteristic (ROC) analysis was conducted and the area under ROC curves (AUCs) was calculated. Sensitivities and specificities were also calculated using the value with the highest Youden Index as the cut-off. A two-tailed $p$-value $<0.05$ was considered statistically significant.

\section{Results}

\section{Characteristics of the study participants}

Table 1 shows major characteristics of the study participants. For both treated and untreated participants, no significant difference was found between active TB and non-TB groups with respect to gender, age, fasting blood glucose and QFT results. However, active TB patients had lower median body mass index (BMI) level (22.46 $\left.\mathrm{kg} / \mathrm{m}^{2}\right)$ than non-TB controls $\left(25.53 \mathrm{~kg} / \mathrm{m}^{2}\right)$ among untreated participants $(p=0.029)$. At baseline, active TB patients showed a trend with higher proportion of IFN- $\gamma$ values $\geq 0.70 \mathrm{IU} / \mathrm{ml}$ than non-TB controls, but such a difference was not statistically significant.

\section{Serum cytokine levels in treated and untreated participants at TO}

Table 2 showed the baseline median level of cytokines among participants with and without TB occurrence classified by preventive treatment. The levels of 10 tested cytokines (LIF, TNF- $\beta$, IL-2, IL-3, IL-5, IL-7, IL-10, IL- 12(p70), IL-12(p40) and IL-15) were below the LDL, they were not included for further data analysis.

The levels of 16 cytokines including Eotaxin, MCP1 (MCAF), SDF- $1 \alpha$, MIP- $1 \beta$, G-CSF, VEGF-A, Basic FGF, IFN- $\gamma$, TNF- $\alpha$, TRAIL, IL-1 $\alpha$, IL-1ra, IL-4, IL-8, IL-9 and IL-17A were significantly higher in active TB patients compared with non-TB controls in both untreated and treated participants at T0. No significant difference was found for the serum levels of the rest 22 cytokines no matter whether preventative treatment conducted.

\section{Performance of the 16 cytokines in predicting active TB development}

To further evaluate the performance on predicting active $\mathrm{TB}$, the AUCs were calculated among untreated participants at T0 (Table 3). Ten cytokines were found to have an $\mathrm{AUC}>0.85$ (Eotaxin $=0.95$, Basic $\mathrm{FGF}=0.96$, GCSF $=0.89$, IFN- $\gamma=0.95$, IL- $1 \alpha=0.92$, IL-1 $\mathrm{ra}=0.85$, IL$4=1.00, \quad$ IL- $8=0.86, \quad$ IL- $9=0.90 \quad$ and $\quad$ TRAIL $=0.88$ ) (Table 3).

\section{Serum levels of the 16 selected cytokines in different time-points}

In treated participants, as compared with level at T0, statistically significant reductions were found for serum levels of Eotaxin, SDF-1 $\alpha$, Basic FGF, IFN- $\gamma$, IL-1ra, IL-4 and IL- 8 in active TB group at T1. For non-TB group, as

Table 1 Characteristics of the participants included in the study

\begin{tabular}{|c|c|c|c|c|c|c|}
\hline & \multicolumn{3}{|l|}{ Treated participants } & \multicolumn{3}{|l|}{ Untreated controls } \\
\hline & $\begin{array}{l}\text { Developed active TB during } \\
\text { follow-up }\end{array}$ & $\begin{array}{l}\text { Kept healthy during } \\
\text { follow-up }\end{array}$ & $\begin{array}{l}p \\
\text { value }\end{array}$ & $\begin{array}{l}\text { Developed active TB during } \\
\text { follow-up }\end{array}$ & $\begin{array}{l}\text { Kept healthy during } \\
\text { follow-up }\end{array}$ & $\begin{array}{l}\mathrm{p} \\
\text { value }\end{array}$ \\
\hline$\overline{\text { Total }^{a}}$ & 12 & 24 & & 9 & 18 & \\
\hline $\begin{array}{l}\text { Median age (Q25-Q75) } \\
\text { (years) }\end{array}$ & $69.00(65.00,72.50)$ & $69.00(65.00,73.00)$ & $0.973^{b}$ & $67.00(62.00,70.00)$ & $67.00(62.00,70.00)$ & $0.979^{b}$ \\
\hline Gender, n (\%) & & & $1.000^{c}$ & & & $1.000^{d}$ \\
\hline Male & $6(50.00)$ & $12(50.00)$ & & $7(77.78)$ & $14(77.78)$ & \\
\hline Female & $6(50.00)$ & $12(50.00)$ & & $2(22.22)$ & $4(22.22)$ & \\
\hline $\begin{array}{l}\text { Median BMI (Q25-Q75) } \\
\left(\mathrm{Kg} / \mathrm{m}^{2}\right)\end{array}$ & $23.54(19.67,26.66)$ & $24.11(21.71,27.25)$ & $0.535^{b}$ & $22.46(20.69,23.88)$ & $25.53(21.81,28.00)$ & $0.029^{b}$ \\
\hline $\begin{array}{l}\text { Fasting blood glucose, } \mathrm{n} \\
(\%)\end{array}$ & & & $0.253^{d}$ & & & $0.539^{d}$ \\
\hline$\geq 7.0 \mathrm{mmol} / \mathrm{L}$ & $2(16.67)$ & $1(4.17)$ & & $0(0.00)$ & $2(11.11)$ & \\
\hline$<7.0 \mathrm{mmol} / \mathrm{L}$ & $10(83.33)$ & $23(95.83)$ & & $9(100.00)$ & $16(88.89)$ & \\
\hline \multicolumn{7}{|c|}{ Median INF-yrelease of QFT (Q25-Q75) (IU/ml) } \\
\hline TO & $2.47(1.76,5.06)$ & $2.79(0.90,4.81)$ & $0.651^{\mathrm{b}}$ & $2.06(1.52,2.81)$ & $1.50(0.92,3.29)$ & $0.520^{b}$ \\
\hline $\mathrm{T} 1$ & $1.52(0.91,3.30)$ & $0.87(0.18,1.91)$ & $0.095^{\mathrm{b}}$ & $0.73(0.63,1.06)$ & $0.63(0.23,1.51)$ & $0.471^{\mathrm{b}}$ \\
\hline \multicolumn{7}{|c|}{ Classified QFT results at T0 (IU/ml), n (\%) } \\
\hline $0.35 \sim 0.70$ & $0(0.00)$ & $4(16.67)$ & $0.279^{d}$ & $1(11.11)$ & $4(22.22)$ & $0.636^{d}$ \\
\hline$\geq 0.70$ & $12(100.00)$ & $20(83.33)$ & & $8(88.89)$ & $14(77.87)$ & \\
\hline
\end{tabular}

Abbreviation: BMI body mass index, Q25 25\% quantile, Q75 75\% quantile, QFT QuantiFERON-TB Gold In-Tube, TB tuberculosis, TO baseline, T1 At the end of

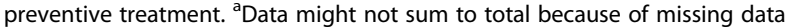

${ }^{b} \mathrm{p}$ for Wilcoxon rank sum test. ${ }^{c} p$ for $x^{2}$ test. ${ }^{d} p$ for Fisher's exact test 


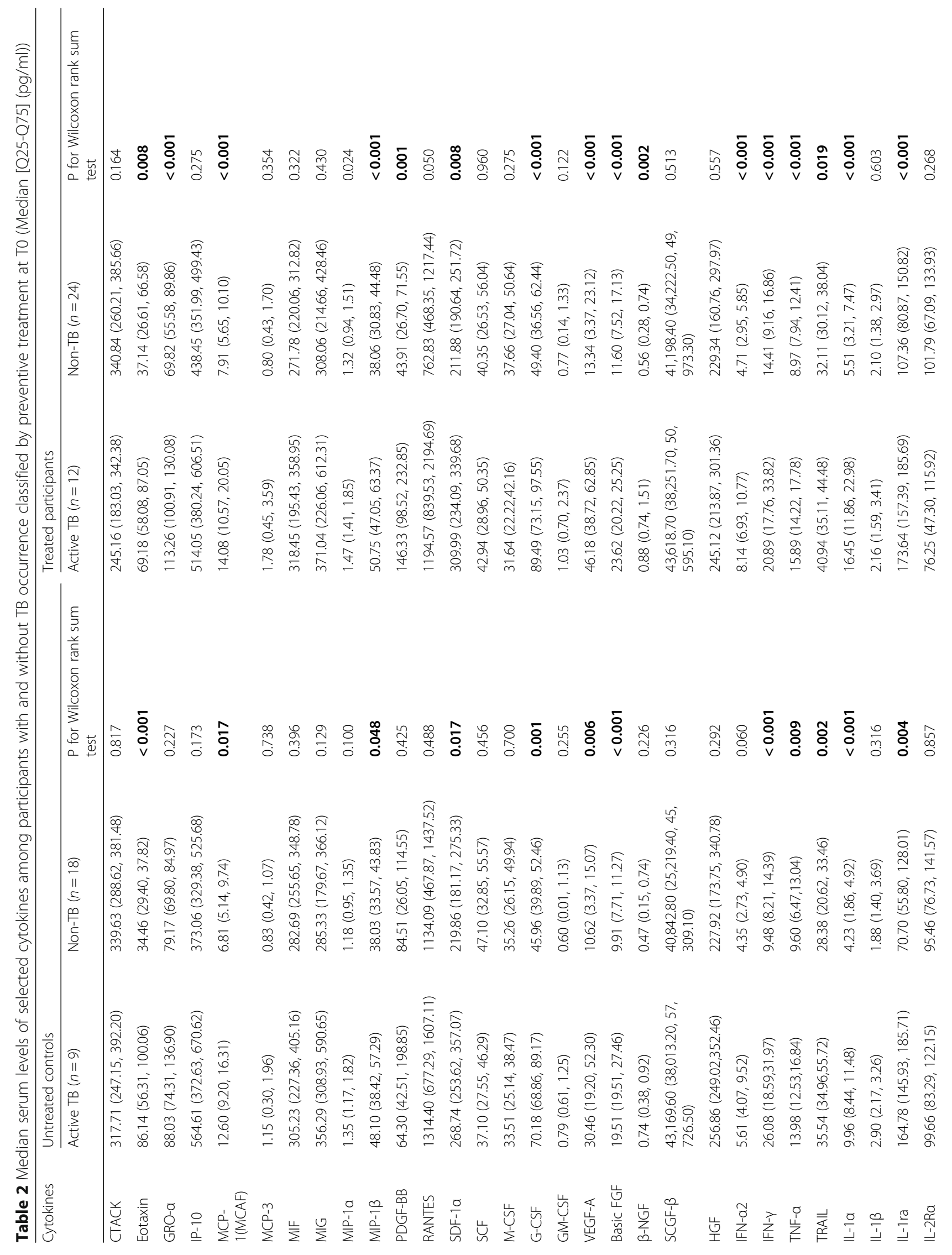




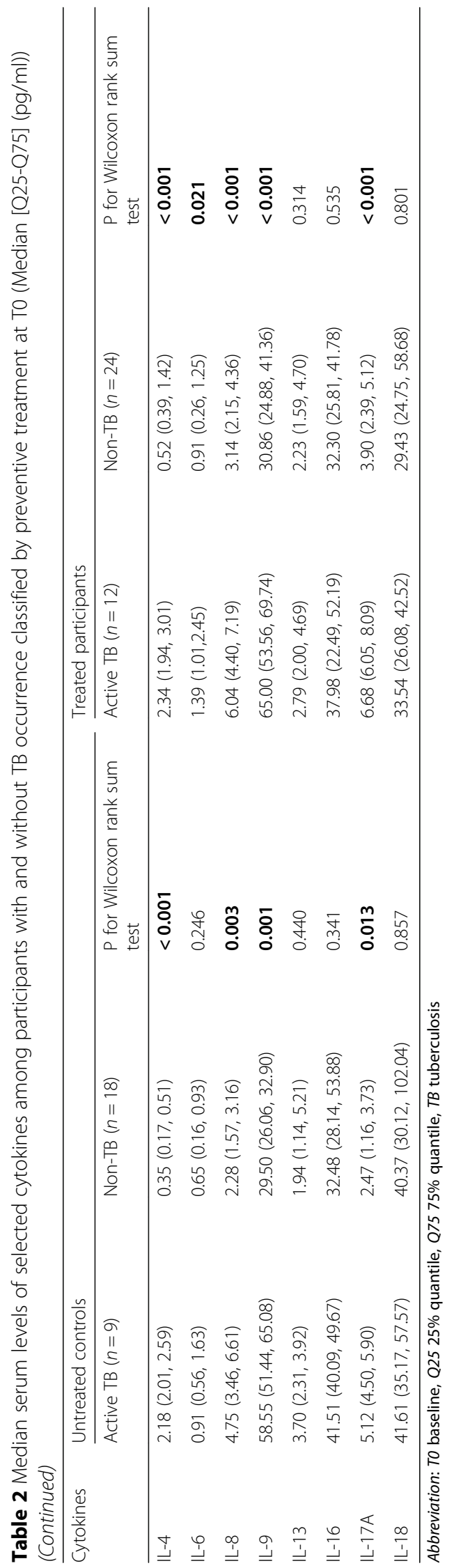


Table 3 Predicting value of the baseline (T0) serum cytokines levels on active TB development among untreated controls

\begin{tabular}{llllll}
\hline Cytokine & AUC $(95 \% \mathrm{Cl})$ & p for z-test & Cut-off $(\mathrm{pg} / \mathrm{ml})$ & Sensitivity, $(95 \% \mathrm{Cl})$ & Specificity, $(95 \% \mathrm{Cl})$ \\
\hline Eotaxin & $0.95(0.87,1.03)$ & $<\mathbf{0 . 0 0 1}$ & 50.54 & $88.89(51.75,99.72)$ & $94.44(72.71,99.86)$ \\
Basic FGF & $0.96(0.88,1.02)$ & $<\mathbf{0 . 0 0 1}$ & 17.49 & $88.89(51.75,99.72)$ & $94.44(72.71,99.86)$ \\
G-CSF & $0.89(0.76,1.02)$ & $\mathbf{0 . 0 0 1}$ & 58.89 & $88.89(51.75,99.72)$ & $88.89(65.29,98.62)$ \\
IFN-Y & $0.95(0.87,1.03)$ & $<\mathbf{0 . 0 0 1}$ & 17.41 & $88.89(51.75,99.72)$ & $94.44(72.71,99.86)$ \\
IL-1a & $0.92(0.82,1.02)$ & $\mathbf{0 . 0 0 1}$ & 8.06 & $88.89(51.75,99.72)$ & $88.89(65.29,98.62)$ \\
IL-1ra & $0.85(0.70,1.00)$ & $\mathbf{0 . 0 0 3}$ & 114.70 & $100.00(66.37,100.00)$ & $72.22(46.52,90.31)$ \\
IL-4 & $1.00(1.00,1.00)$ & $<\mathbf{0 . 0 0 1}$ & 1.16 & $100.00(66.37,100.00)$ & $100.00(81.47,100.00)$ \\
IL-8 & $0.86(0.73,1.00)$ & $\mathbf{0 . 0 0 2}$ & 3.44 & $77.78(39.99,97.19)$ & $83.33(58.58,96.42)$ \\
IL-9 & $0.90(0.77,1.04)$ & $\mathbf{0 . 0 0 1}$ & 38.85 & $88.89(51.75,99.72)$ & $94.44(72.71,99.86)$ \\
IL-17A & $0.80(0.63,0.98)$ & $<\mathbf{0 . 0 0 1}$ & 3.48 & $100.00(66.37,100.00)$ & $72.22(46.52,90.31)$ \\
MCP-1(MCAF) & $0.79(0.59,0.99)$ & $\mathbf{0 . 0 1 6}$ & 10.34 & $66.67(29.93,92.51)$ & $83.33(58.58,96.42)$ \\
MIP-1 $\beta$ & $0.75(0.55,0.94)$ & $\mathbf{0 . 0 4 0}$ & 57.65 & $55.56(21.20,86.30)$ & $94.44(72.71,99.86)$ \\
SDF-1a & $0.79(0.61,0.97)$ & $\mathbf{0 . 0 1 6}$ & 218.00 & $100.00(66.37,100.00)$ & $50.00(26.02,73.98)$ \\
TNF-a & $0.82(0.66,0.97)$ & $\mathbf{0 . 0 0 9}$ & 10.48 & $100.00(66.37,100.00)$ & $61.11(35.75,82.70)$ \\
TRAIL & $0.88(0.74,1.01)$ & $\mathbf{0 . 0 0 2}$ & 34.51 & $77.78(39.99,97.19)$ & $88.89(65.29,98.62)$ \\
VEGF-A & $0.83(0.66,1.00)$ & $\mathbf{0 . 0 0 6}$ & 14.31 & $88.89(51.75,99.72)$ & $72.22(46.52,90.31)$ \\
\hline Abbrevian & & & &
\end{tabular}

Abbreviation: $A U C$ area under curve, $T B$ tuberculosis

compared with T0, there were statistically significant decreases in serum levels of Eotaxin, SDF-1 $\alpha$, TRAIL, IL1ra and IL-8 while increases for MIP-1 $\beta$ and IL-9 (Table 4).

In untreated participants, as compared with level at T0, statistically significant reductions in serum levels of Eotaxin, SDF- $1 \alpha$, IL- 4 and IL- 8 were found in active TB group at T1. For non-TB group, as compared with T0, there were statistically significant decreases in serum levels of SDF- $1 \alpha$ and IL- 8 while increases for MIP- $1 \beta$ and IL-9 (Table 4).

As shown in Fig. 1, only the median level of IL-1ra declined significantly from $\mathrm{T} 0(173.64 \mathrm{IU} / \mathrm{ml})$ to $\mathrm{T} 1$ $(126.44 \mathrm{IU} / \mathrm{ml})$ in active TB group $(p=0.002)$ and from T0 $(107.36 \mathrm{IU} / \mathrm{ml})$ to $\mathrm{T} 1(95.66 \mathrm{IU} / \mathrm{ml})$ in non-TB group $(p=0.009)$ among treated participants. No statistically significant difference was found for IL-1ra level at T1 as compared with $\mathrm{T} 0$ both in active TB and non-TB groups among untreated participants $(p=0.078$ for active TB group, $p=0.265$ for non-TB group) (Table 4 ).

\section{Discussion}

Our results provided new insight into using serum cytokines as biomarkers to evaluate host responses to LTBI preventative treatment. The baseline serum levels of 16 cytokines were found to be significantly higher in those developed active TB laterly as compared with non-TB controls in both untreated and treated participants. Among them, in particular, IL-1ra responses declined significantly after treatment in treated participants, suggesting a predisposing role as biomarker to predict the development of active TB.

To our knowledge, only a handful of studies ever explored the relationship between cytokines and TB development. A study from Amsterdam cohort reported that the expression of IL-13 could predict the development of TB within months before the onset of clinical symptoms among HIV-infected individuals [16-18]. Another prospective study found that IP-10 levels in active patients were higher than in household and community controls [19]. A subsequent study conducted in participants with HIV-TB and active TB made similar observations, which reported that blood IP-10 levels were significantly higher in active TB patients than in controls, regardless of HIV infection [20]. Such previous findings were not observed in our study, different demographic and clinical characteristics of the study participants and different time points selected for cytokine measurements might result in the inconsistence. As most of the previous studies compared the level of cytokines between active TB patients and LTBI participants through case-control design, the influence of individual difference within group on the cytokines response could not be excluded [21-25]. Our longitudinal cohort-based study provides more solid evidence using dynamic changes of the serum cytokines in the same person. However, study with large samples size are needed to verify the current result.

Our study showed that the level of IL-1ra declined significantly during therapy both in active $\mathrm{TB}$ and non-TB 


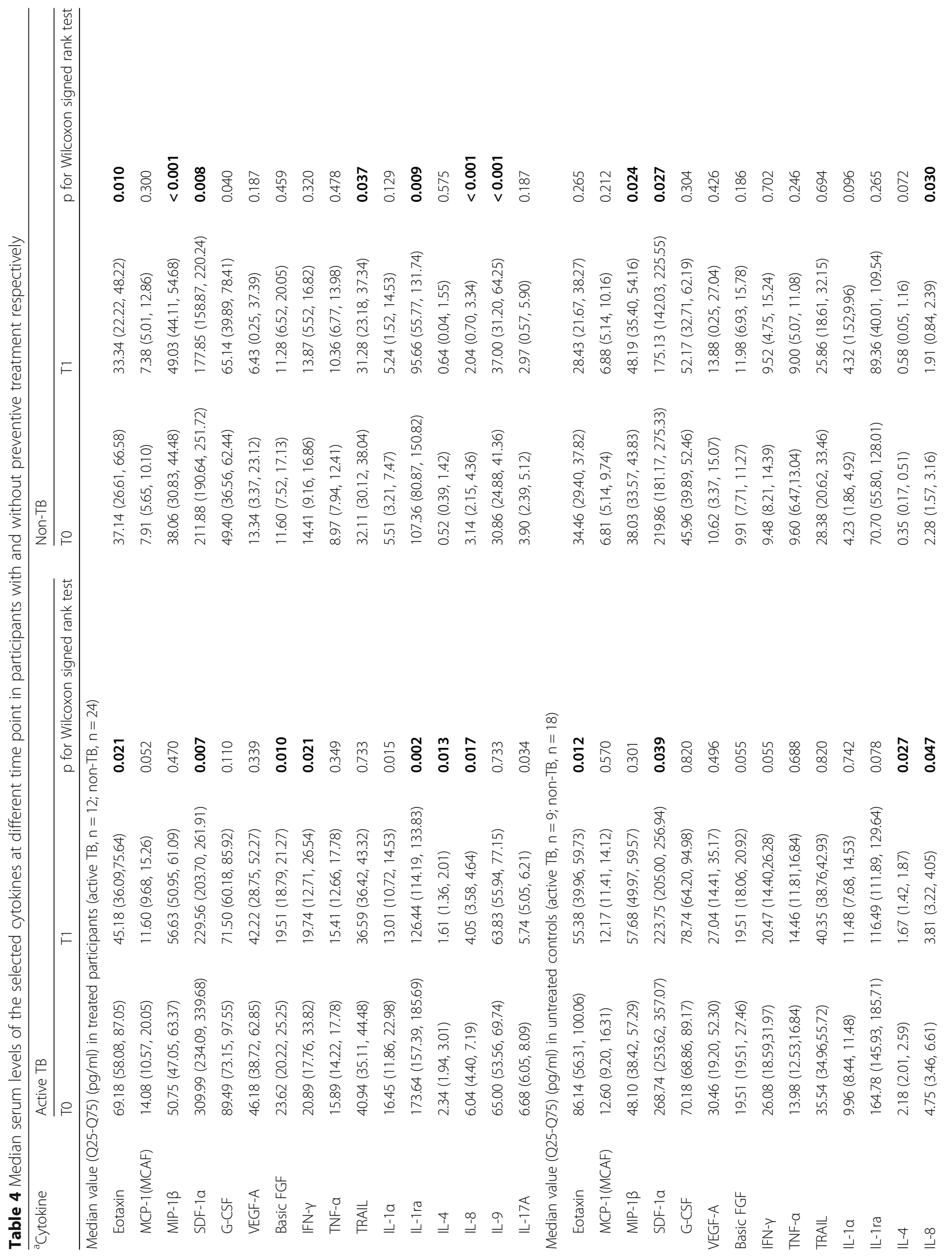




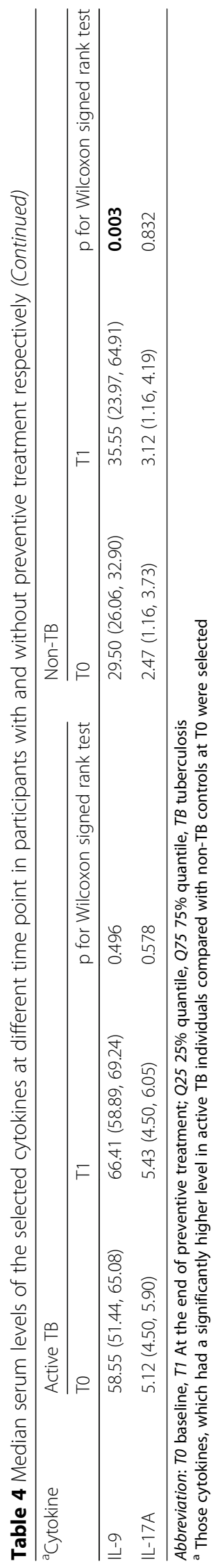




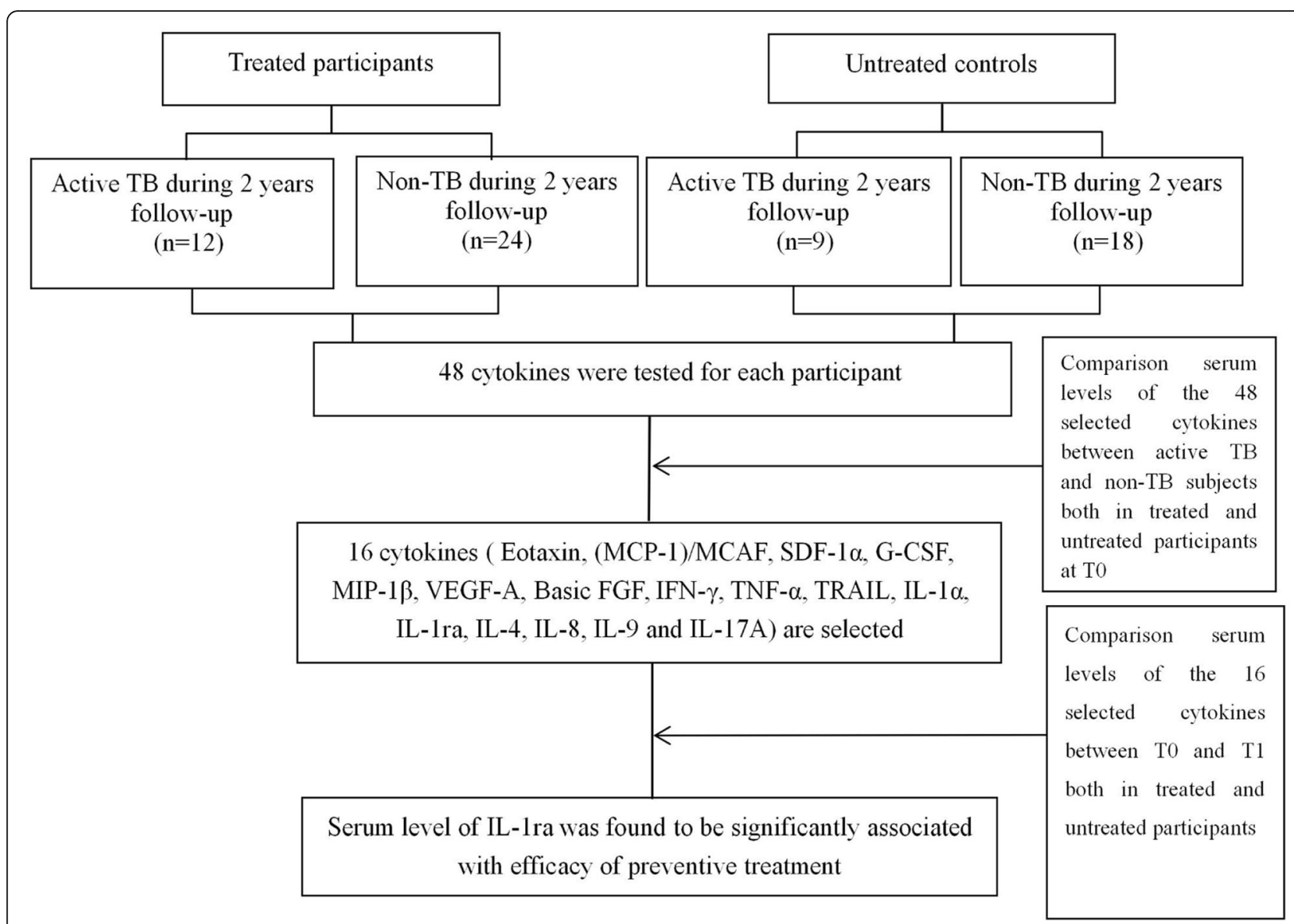

Fig. 1 Flow chart to identify the relation between serum cytokines level and preventive treatment efficacy. A total of 12 active TB cases and 24 non-TB individuals from treated participants as well as 9 active TB cases and 18 non-TB individuals from untreated controls, paired by gender and age, were included in the present study. The levels of 16 cytokines were significantly higher in active TB cases as compared with non-TB controls both in treated participants and untreated controls at T0. Only the level of IL-1ra declined significantly from T0 to T1 in treated participants, but not in untreated controls

groups. But such a difference was not observed for untreated participants. It was consistent with a prospective study which observed a statistically significant decline in IL-1ra responses at 6 and 9 months after treated with isoniazid for 9 months in participants with LTBI [12]. Our results showed the decline occurred as early as 1 week after the treatment, which suggested a possibility that IL-1ra level might be used for real-time treatment effect monitoring. IL-1ra is a cytokine produced by monocytes, macrophages, and dendritic cells, which prevents the binding of IL- $1 \alpha$ as well as IL- $1 \beta$ to IL-1R1 by competitively blocking IL-1RI receptors [26, 27]. IL-1ra expression played an important role during mycobacterial antigen-elicited granuloma formation, an immune and physical barrier to contain the infection and prevent MTB dissemination [28, 29]. A prospective study conducted in active TB cases found that serum IL-1ra concentrations were significantly reduced after anti-TB treatment and the level of IL-1ra was higher in patients with delayed treatment response than those with good response to therapy [30]. These studies consistently suggested that IL-1ra might be potential correlates of successful treatment in both active TB and LTBI individuals. Our results provide novel insight into using IL-1ra as an early prognosis biomarker to evaluate the performance of the preventive treatment. Besides, it was recently reported that M.tb-infected mice receiving anti-IL-1ra antibody had significantly lower bacterial burdens in their lungs as compared to PBS-treated controls [31]. Additionally, patients with rheumatic diseases receiving monoclonal IL-1ra antibodies had a significantly increased risk of TB re-activation [32]. These findings provide further evidence to support the relation between higher levels of baseline IL-1ra and the risk of developing active TB observed in our study. However, cytokine measurements were not repeated at the time of diagnosis of active TB in our study, whether serum level of IL-1ra could differentiate active TB and LTBI needs to be further verified. 
When interpreting the results of the study, some limitations should be kept in mind. First, although we used the same Luminex kit to test serum samples collected at different time points, the influence of storage time on sample quality could not be completely ruled out. Second, considering the feasibility of monitoring peripheral blood cytokines after preventive treatment un-stimulated serum samples were measured in our study. Therefore, the dynamic change of cytokine concentrations observed in our study might could not accurately reflect the changes in immune levels caused by TB-specific pathogens. Our results needs to be verified by further study with larger sample size and with specific antigen stimulated samples [33]. Third, due to the limited sample size, we pooled the treated participants who were treated with different regimens for analysis, which might have an impact on the outcomes. Fourth, as the RCT targeting elder population with attenuation of immunity, generalization of the study results should be cautious. Fifth, in order to avoid potential confounding effect, controls not developed active TB were matched with cases by age and gender, but bias caused by other potential confounders could not be excluded in our study [6].

\section{Conclusions}

Our results suggested that serum level of IL-1ra decreased along with preventive treatment and might be used to predict disease progression. It provided a clue for exploring prognosis biomarkers to evaluate the performance of LTBI treatment, but our findings needs further verification by studies with larger sample size in different populations.

\section{Abbreviations \\ LTBI: Latent tuberculosis infection; TB: Tuberculosis; M.tb: Mycobacterium tuberculosis; TST: Tuberculin skin test; IGRAs: Interferon- $\gamma$ Release Assays; QFT: QuantiFERON TB Gold In-Tube; IP-10: Interferon-inducible protein - 10; MCP-1: Macrophage chemoattractant protein-1; MIP-1a: Macrophage inflammatory protein-1a; GM-CSF: Granulocyte macrophage colony stimulating factor; ROC: Receiver operating characteristic; AUCs: Area under ROC curves}

\section{Acknowledgments}

We thank all the investigators from the study sites for their contribution to the field work and sample collection.

\begin{abstract}
Authors' contributions
L.G1 designed the study. HR. Z, XF. C, HN. X, JM.L, SG. P, L.G2, F. S, ZS.L, DK. W, XL.G, JX. Y, BX.F and Q. J were in charge of data management. HR. Z, XF. C and L.G1 did data analysis and wrote the report. HR. Z, XF. C, HN. X and N. $L$ participated in the data interpretation. Q. J commented on the report and improved English writing. JM. L, SG.P, L.G2, HN. X, F.S, ZS. L, DK.W, XL. G, JX.Y, $B X . F$ and $N$. L organized investigations at the study sites. All authors contributed to review and revision and have seen and approved the final version of manuscript.
\end{abstract}

\section{Funding}

This work was supported by the Program for National Natural Science Foundation of China (grant no.81702052). The funding bodies do not have any role in the design of the study and collection, analysis, and interpretation of data and in writing the manuscript.

\section{Availability of data and materials}

The datasets used and/or analysed during the current study are available from the corresponding author on reasonable request.

Ethics approval and consent to participate

The protocol of the present study has been approved by the Ethics Committees of the Institute of Pathogen Biology, Chinese Academy of Medical Sciences (IDs: IPB-2015-5 and IPB-2016-8). All participants have signed the written informed consent.

\section{Consent for publication}

Not applicable.

\section{Competing interests}

The authors declare that they have no competing interests. L. G promises that he had no communication with other editors about this article, and would strictly abide by the rules of this journal and not participate in the review PROCESS.

\section{Author details}

${ }^{1} \mathrm{NHC}$ Key Laboratory of Systems Biology of Pathogens, Institute of Pathogen Biology, and Center for Tuberculosis Research, Chinese Academy of Medical Sciences and Peking Union Medical College, No. 9 Dong Dan San Tiao, Dongcheng District, Beijing 100730, China. ${ }^{2}$ The Sixth People's Hospital of Zhengzhou, Zhengzhou 450061, China. ${ }^{3}$ The Center for Disease Prevention and Control of Zhongmu County, Zhengzhou 451470, China.

${ }^{4}$ Gastroenterology Department, PLA Rocket Force Characteristic Medical Center, Beijing 100088, China.

Received: 11 March 2020 Accepted: 21 April 2020

Published online: 08 May 2020

\section{References}

1. World Health Organization. Global tuberculosis report 2018[Z]. Geneva: World Health Organization; 2018.

2. Hartman-Adams H, Clark K, Juckett G. Update on latent tuberculosis infection. Am Fam Physician. 2014;89:889-96.

3. Leung CC, Rieder HL, Lange C, Yew WW. Treatment of latent infection with mycobacterium tuberculosis: update 2010. Eur Respir J. 2011;37:690-711.

4. International Union Against Tuberculosis Committee on Prophylaxis. Efficacy of various durations of isoniazid preventive therapy for tuberculosis: five years of follow-up in the IUAT trial. International Union Against Tuberculosis Committee on Prophylaxis. Bull World Health Organ. 1982;60:555-64.

5. Stagg HR, Zenner D, Harris RJ, Muñoz L, Lipman MC, Abubakar I. Treatment of latent tuberculosis infection: a network meta-analysis. Ann Intern Med. 2014;161:419-28.

6. Gao L, Zhang H, Xin H, Liu J, Pan S, Li X, et al. Short-course regimens of rifapentine plus isoniazid to treat latent tuberculosis infection in older Chinese patients: a randomised controlled study. Eur Respir J. 2018;52: 1801470.

7. Zellweger JP, Sotgiu G, Block M, Dore S, Altet N, Blunschi R, et al. Risk assessment of tuberculosis in contacts by IFN- $\gamma$ release assays. A tuberculosis network European trials group study. Am J Respir Crit Care Med. 2015;191:1176-84.

8. Rangaka MX, Wilkinson KA, Glynn JR, Ling D, Menzies D, MwansaKambafwile J, et al. Predictive value of interferon- $\gamma$ release assays for incident active tuberculosis: a systematic review and meta-analysis. Lancet Infect Dis. 2012;12:45-55.

9. Slight SR, Khader SA. Chemokines shape the immune responses to tuberculosis. Cytokine Growth Factor Rev. 2013;24:105-13.

10. Eum SY, Lee YJ, Min JH, Kwak HK, Hong MS, Kong JH, et al. Association of antigen-stimulated release of tumor necrosis factor-alpha in whole blood with response to chemotherapy in patients with pulmonary multidrugresistant tuberculosis. Respiration. 2010;80:275-84.

11. Mvungi HC, Mbelele PM, Buza JJ, Mpagama SG, Sauli E. Blood cytokine responses to early secreted protein antigen-6/culture filtrate protein-10 tuberculosis antigens 2 months after antituberculosis treatment among patients with drug-susceptible pulmonary tuberculosis. Int J Mycobacteriol. 2019;8:53-9. 
12. Clifford V, Tebruegge M, Zufferey C, Germano S, Forbes B, Cosentino L, et al. Mycobacteria-specific cytokine responses as correlates of treatment response in active and latent tuberculosis. J Inf Secur. 2017;75:132-45.

13. Leem AY, Song JH, Lee EH, Lee H, Sim B, Kim SY, et al. Changes in cytokine responses to TB antigens ESAT-6, CFP-10 and TB 7.7 and inflammatory markers in peripheral blood during therapy. Sci Rep. 2018;8:1159.

14. Kabeer BS, Raja A, Raman B, Thangaraj S, Leportier M, Ippolito G, et al. IP-10 response to RD1 antigens might be a useful biomarker for monitoring tuberculosis therapy. BMC Infect Dis. 2011;11:135.

15. Xin H, Zhang H, Cao X, Li X, Li M, Feng B, et al. Serum level of IL-8 is associated with reversion of QuantiFERON-TB gold in-tube tests. J Inf Secur. 2019;78:292-8.

16. Sloot R, Schim van der Loeff MF, Kouw PM, Borgdorff MW. Yield of tuberculosis contact investigations in Amsterdam: opportunities for improvement. Eur Respir J. 2014;44:714-24.

17. Sloot R, Schim van der Loeff MF, van Zwet EW, Haks MC, Keizer ST, Scholing $\mathrm{M}$, et al. Biomarkers can identify pulmonary tuberculosis in HIV-infected drug users months prior to clinical diagnosis. EBioMedicine. 2014;2:172-9.

18. Sloot R, van der Loeff MF S, Kouw PM, Borgdorff MW. Risk of tuberculosis after recent exposure. A 10-year follow-up study of contacts in Amsterdam. Am J Respir Crit Care Med. 2014;190:1044-52.

19. Azzurri A, Sow OY, Amedei A, Bah B, Diallo S, Peri G, et al. IFN-y-inducible protein 10 and pentraxin 3 plasma levels are tools for monitoring inflammation and disease activity in mycobacterium tuberculosis infection. Microbes Infect. 2005;7:1-8.

20. Petrone L, Cannas A, Vanini V, Cuzzi G, Aloi F, Nsubuga M, et al. Blood and urine inducible protein 10 as potential markers of disease activity. Int J Tuberc Lung Dis. 2016;20:1554-61.

21. Suzukawa $M$, Akashi $S$, Nagai $H$, Nagase $H$, Nakamura $H$, Matsui $H$, et al. Combined Analysis of IFN- $\gamma$, IL-2, IL-5, IL-10,IL-1 ra and MCP-1 in QFT Supernatant Is Useful for Distinguishing Active Tuberculosis from Latent Infection. PLoS One. 2016;11:e0152483.

22. Frahm M, Goswami ND, Owzar K, Hecker E, Mosher A, Cadogan E, et al. Discriminating between latent and active tuberculosis with multiple biomarker responses. Tuberculosis (Edinb). 2011;91:250-6.

23. Tebruegge M, Dutta B, Donath S, Ritz N, Forbes B, Camacho-Badilla K, et al Mycobacteria-specific cytokine responses detect tuberculosis infection and distinguish latent from active tuberculosis. Am J Respir Crit Care Med. 2015; 192:485-99.

24. Harari A, Rozot V, Bellutti Enders F, Perreau M, Stalder JM, Nicod LP, et al Dominant TNF-alpha+ mycobacterium tuberculosis-specific CD4+ T cell responses discriminate between latent infection and active disease. Nat Med. 2011;17:372-6.

25. Clifford V, Tebruegge M, Zufferey C, Germano S, Forbes B, Cosentino L, et al. Cytokine biomarkers for the diagnosis of tuberculosis infection and disease in adults in a low prevalence setting. Tuberculosis (Edinb). 2019;114:91-102.

26. Dinarello CA. Interleukin-1 in the pathogenesis and treatment of inflammatory diseases. Blood. 2011;117:3720-32.

27. Arend WP. The balance between IL-1 and IL-1Ra in disease. Cytokine Growth Factor Rev. 2002;13:323-40.

28. Ruth JH, Bienkowski M, Warmington KS, Lincoln PM, Kunkel SL, Chensue SW IL-1 receptor antagonist (IL-1 ra) expression, function, and cytokine-mediated regulation during mycobacterial and schistosomal antigen-elicited granuloma formation. J Immunol. 1996;156:2503-9.

29. Lin PL, Flynn JL. Understanding latent tuberculosis: a moving target. J Immunol. 2010;185:15-22.

30. Lee $\mathrm{JH}$, Chang $\mathrm{JH}$. Changes of plasma interleukin-1 receptor antagonist, interleukin-8 and other serologic markers during chemotherapy in patients with active pulmonary tuberculosis. Korean J Intern Med. 2003;18:138-45.

31. Ji DX, Yamashiro LH, Chen KJ, Mukaida N, Kramnik I, Darwin KH, et al. Type I interferon-driven susceptibility to mycobacterium tuberculosis is mediated by IL-1Ra. Nat Microbiol. 2019;4:2128-35.

32. Settas LD, Tsimirikas G, Vosvotekas G, Triantafyllidou E, Nicolaides P. Reactivation of pulmonary tuberculosis in a patient with rheumatoid arthritis during treatment with IL-1 receptor antagonists (anakinra). J Clin Rheumatol. 2007;13:219-20.

33. Clifford V, He Y, Zufferey C, Connell T, Curtis N. Interferon gamma release assays for monitoring the response to treatment for tuberculosis: a systematic review. Tuberculosis (Ed-inb). 2015;95:639-50.

\section{Publisher's Note}

Springer Nature remains neutral with regard to jurisdictional claims in published maps and institutional affiliations.
Ready to submit your research? Choose BMC and benefit from:

- fast, convenient online submission

- thorough peer review by experienced researchers in your field

- rapid publication on acceptance

- support for research data, including large and complex data types

- gold Open Access which fosters wider collaboration and increased citations

- maximum visibility for your research: over $100 \mathrm{M}$ website views per year

At BMC, research is always in progress.

Learn more biomedcentral.com/submissions 